\title{
Introduction to LEP (Local Enterprise Partnership) in British Planning System: A new dimension towards Planning Policies
}

\author{
Anurag Kumar \\ M2RI, International Masters, Department a'menagement, Ecole Polytechnique, University Francois Rabellias, \\ Tours, France
}

\begin{abstract}
The UK National Strategic Reference Framework (UKNSRF) (DTI, 2006) provided an overview about regional issues and how Government defined the regional problem and its underlying causes. The approach was in line with that described in A Modern Regional Policy for the United Kingdom (HM Treasury, $2003)^{l}$. Since there is a disparity in progress among different regions, there are a number of different ways in which regional development problems can be conceptualized but in its National Strategic Framework the UK Government argued that the less-well off regions were growing too slowly relative to the more prosperous regions. The causes of their relatively poor growth were identified as a lack of relative competitiveness. That means that many regions lack productivity in terms economy and they are not self sustained but depend heavily on public funding.

To enhance their competitiveness requires measures to enhance the growth of their productivity and to increase their ability to use their labour more effectively (as measured by their employment rate). It is generally recognized that the ability of regions to grow is influenced by their economic structure and the quality of their resource base. Across the United Kingdom, some regions have found it hard to shake-off the legacy of the past and secure higher value added sectors to replace their declining industrial sectors. An inability to secure new investment from the private sector has often meant that the less prosperous regions have become relatively heavily dependent on the public sector for income and jobs, a factor to which we return below.

To achieve the social \& economic balance across the regions, the government issues a new localism act in 2011. It is called Local Enterprise Partnership(LEP).
\end{abstract}

\section{Introduction}

The New-Localism and Local enterprise Partnership's:

The Localism Act 2011 (c. 20) is an Act of Parliament that changes the powers of local government in England. The measures affected by the Act include more elected mayors, referendums and the "Local authority's general power of competence" (Part 1, chapter 1) which states "A local authority has power to do anything that individuals generally may do".

In England, a Local enterprise partnership is a partnership between local authorities and businesses formed in 2011 to help determine local economic priorities and lead economic growth and job creation within its local area. They carry out some of the functions previously carried out by the regional development agencies which were abolished in March 2012 Local enterprise partnerships are led by local authorities and businesses across natural economic areas. They provide the vision, knowledge and strategic leadership needed to drive sustainable private sector growth and job creation in their area. The Local Growth White Paper set out the diverse roles the local enterprise partnerships can play depending on their local priorities. These could include ensuring that planning and infrastructure investment support business needs, and working with Government to support enterprise, innovation, global trade and inward investment By combining strong business leadership with groups of local authorities whose planning, regulatory and public realm roles are critical to growth, these bodies will be able to bring an integrated approach across real economic geographies. This will be a major step forward in fostering a strong environment for business growth.

The present - After the abolition of regional level and the Local Enterprise Partnership's an overview Initiation and functions -a critical review ${ }^{2}$ :

The intention to establish LEPs was announced in the Queen's speech and was set out in the May 2010 proposal for the Decentralisation and Localism Bill (DCLG, 2010a). However, in the language of Donald

1 www.hmtreasury.gov.uk/consultations_and_legislation/modern_regional_policy)

${ }^{2}$ LEPs: Local enterprise partnerships are led by local authorities and businesses across natural economic areas. They provide the vision, knowledge and strategic leadership needed to drive sustainable private sector growth and job creation in their area. 
Rumsfeld, LEPs embody 'known unknowns' and 'unknown unknowns' (Ward, 2010). There is little or no information about the precise terms of reference for LEPs, funding or administrative arrangements, about who is to host them, whether the executive role is to be carried out by the local authority or whether LEPs are to be set up as private sector economic development companies. Still less is known about precisely what the LEPs will do and what freedom of action they will have.Will they be able to act or spend themselves or will they rely on accountable bodies? The proposal for LEPs, however, was as much about abolishing the RDAs as it is about localism (BBC Front Page, 2010). At the time of writing, we are expecting a White Paper setting out Government plans for a new approach to sub-national growth, a Localism Bill to come before Parliament, and the results of the comprehensive spending review, showing the extent of the public sector cutbacks, to be revealed on 20 October (Larkin, 2010). There are rumours, however, that the publication of the White Paper will be delayed. We can look at what was known by September 2010 about membership, role and function, size, budget of LEPs and the timescale for their introduction.

\section{Membership and Governance of the LEPs}

The Coalition Government's Programme said, We will support the creation of Local Enterprise Partnerships - joint local authority-business bodies brought forward by local authorities themselves to promote local economic development' (HMG, 2010a, p. 10). An open letter to local authority and business leaders and local authority Chief Executives sent in June 2010, Vince Cable, Minister for Business, Innovation and Skills and Eric Pickles, Minister for Communities and Local Government, invited local groups of councils and business leaders to come together to consider how they wished to form local enterprise partnerships (DCLG, $2010 \mathrm{a}, \mathrm{b}) .^{3}$ They were to involve only upper-tier authorities; this to avoid ministers receiving a host of bids from groups of districts. The requirement to involve at least two upper-tier authorities was subsequently set aside (Hayman, 2010). Half the LEP board members were to be drawn from industry/local commerce and led by a local businessperson, to reflect the importance of private sector investment and expertise. Colleges and Universities were also to be involved in the partnerships as well as other stakeholders. The Third Sector and the voluntary sector were promised a seat on the board but this has yet to be seen and is a promise that can be broken. Intuitively however, it looked like LEPs would be similar to the RDAs, with a Board to act as the directors of an agency with staff and that they would commission delivery of services. The Government wants change in public service delivery, in line with the idea of the 'Big Society', and it was said that governance structures needed to be sufficiently robust and clear, to ensure proper accountability for delivery by partnerships but, it is not clear precisely what form LEPs will take.

\section{Role and Functions of the LEPs}

The consultation document on the new Regional Growth Fund says the following about the role of LEPs: We anticipate that local enterprise partnerships will wish to provide the strategic leadership and long-term vision for the private sector-led economic renewal of their area .Partnerships will see business working in equal partnership with civic leaders to drive real change in local public service delivery to create a better business environment in their area. (our emphases)(HMG, 2010b) The LEPs are to have a strategic role in creating the right environment for business and growth in their locality. LEPs are to be responsible principally for business support and enterprise. However, LEP functions are likely to include enterprise and business support, investment in local economic infrastructure, employment and workless ness, skills, planning, housing and, possibly, tourism and the transition to a low carbon economy. It is envisaged that a LEP will also have a planning, housing and transport function; confusingly, lower-tier authorities hold many of the powers in the latter three policy areas (Marrs, 2010a). However, we need to be clear on what delegated powers LEPs will have on local authorities and how the LEPs are to be accountable to local authorities for decision making on economic development, planning and regeneration. Furthermore, given that coordination between Department of Communities and Local Government (DCLG), Department for Business, Innovation \& Skills (BIS) and Department of Education (DE) has been poor, it is not clear for example how skills policy and LEPs are to work, let alone sectoral policies and still less Big Society.

\section{Size and Geographical Scale}

LEPs are to "better reflect the natural economic geography of the areas they serve and hence to cover real functional economic and travel to work areas' (DCLG, 2010a). This can be seen as a criticism of the RDAs

\footnotetext{
${ }^{3}$ From RDAs to LEPs: A New Localism? Case Examples of West Midlands and Yorkshire - Gill Bentley David Bailey and John Shutt Local Economy September 2010 vol. 25 no. 7 535-557
} 
which are based on administrative and not functional regions. Administrative regions were chosen as the basis for the RDAs because New Labour did not want a long debate about boundaries to delay the inception of the $\mathrm{RDAs}^{4}$. The Cable-Pickles letter, however, does suggest that if a LEP for a functional economic area matches existing regional boundaries, there will be no objection to such a proposal.

This implies that an RDA could transform into a LEP. The Coalition agreement even said that LEPs 'may take the form of the existing RDAs in areas where they are popular' (HMG, 2010a). Yet at the same time, the coalition government proposes to dismantle the regional tier of institutions. The budget speech indicated that the creation of LEPs will be particularly supported 'around England's major cities' (Larkin, 2010). City regions may come to the fore instead, assuming that local authorities can actually agree on this. Given that local authorities have already carried out local economic assessments for functional economic areas, under Labour Government policy, it was likely that many LEPs would be based on the areas as defined by the Local Economic Assessments. They could also be made up of localities that have made Multi- Area Agreements.

\section{Budget}

LEPs are expected to operate on a 'task and finish' basis whereby they will bid to Government for funds for specific projects, rather than handling the multi-million pound budgets that are currently given to RDAs. Indeed, LEPs were initially expected to bid for the newly set up Regional Growth Fund, which is worth £1bn over 2011-12 and 2012-13 (HMG, 2010b).This is roughly 65\% less than the RDA networks budget. Initially it was thought that it was likely to be divided into two pots: a challenge fund that will be subject to competitive bidding for capital investment grants or loans, and a second pot to be allocated to LEPs through a funding formula (Hayman, 2010) ${ }^{5}$. However, Sir Ian Wrigglesworth, deputy chairman of the fund and Port of Tyne chairman, has added to the general confusion by saying that LEPs should not get any of the $£ 1$ bn Regional Growth Fund and that the Fund should be directed solely towards growing private sector businesses - especially in areas with a weak private sector (Finch, 2010).

\section{The fund has two main objectives:}

To encourage private sector enterprise by providing support for projects with significant potential for economic growth and create additional sustainable private sector employment, and to support in particular those areas and communities that are currently dependent on the public sector make the transition to sustainable private sector led growth and prosperity. Bids for the RGF are expected to comprise a 'package of projects 'brought together by the LEPs that are: 'transformational' in nature; focused on boosting private sector employment; able to demonstrate 'significant private sector leverage'; address a 'clear market failure'; backed by the community; and able to contribute to 'green economic growth' (HMG, 2010b). The bids to win funding will be decided by former deputy prime minister Lord Heseltine, along with Sir Ian Wigglesworth (Hayman, 2010). Wigglesworth has also said that regional bodies in some regions could play a role in vetting how the Regional Growth Fund is disbursed, and that he favours fewer but larger grants rather than having the fund divided up into a large number of small grants and distributed around the country (Hickey, 2010a; Bailey, 2010b). It is not clear therefore whether funding will be available to the LEPs or for the running costs of LEPs. However, the Minister has hinted that there would be another other source of funding - perhaps the remainder of the RDA budget - available to fund the partnerships, the details of which are likely to be in the proposed white paper (Hayman, 2010). There may also be scope for LEPs to raise their own funds, although so far only hints have been dropped in this direction.

\section{Timescale $^{6}$}

Proposals for LEPs had to be presented to Government by 6 September 2010. The transition from RDAs to LEPs can be broken down into three discrete phases:

Sept 2010 - Sept 2011: Respond to proposals and facilitate establishment of LEPs

Oct 2011 - April 2012: 'Terminate' and 'transfer' RDA functions; complete

RDA stand-alone major projects

July 2010 - April 2012: Disposal of RDA assets

\footnotetext{
${ }^{4}$ From RDAs to LEPs: A New Localism? Case Examples of West Midlands and Yorkshire - Gill Bentley David Bailey andJohn Shutt Local Economy September 2010 vol. 25 no. 7 535-557

${ }^{5}$ From RDAs to LEPs: A New Localism? Case Examples of West Midlands and Yorkshire - Gill Bentley David Bailey andJohn Shutt Local Economy September 2010 vol. 25 no. 7 535-557

${ }^{6}$ From RDAs to LEPs: A New Localism? Case Examples of West Midlands and Yorkshire - Gill Bentley David Bailey and John Shutt Local Economy September 2010 vol. 25 no. 7 535-557
} 
Given the timescale for the introduction of the LEPs and the need to be operational, 'Shadow' versions of LEPs are to be in place before the end of the year and to be in place for a 1 April 2011 start to enable groups of councils to bid for cash from the Regional Growth Fund (Carpenter, 2010a).

\section{The progress of LEP's: ${ }^{7}$}

Local enterprise partnerships are locally led and their activities are driven by local economic circumstances and priorities. Government has been very careful not to impose a central view on what those priorities should be.

LEPs are developing at different speeds but all are identifying the barriers to local growth, setting out their priorities for the local area and then moving towards delivering against those priorities by:

- Directly tackling the barriers to local growth in their areas, for example: Coventry and Warwickshire LEP's Access to Finance group which has got local banks working together, backed up by practical seminars and financial surgeries;

- Worcestershire LEP's Business Development Forum for companies experiencing delays and barriers in the planning system; and Leicester and Leicestershire LEP have embarked on a project to develop a new relationship between businesses and regulators in their area.

- Maximising the benefits of national initiatives like enterprise zones and the growing places fund.

- Working with national policy leads on how local needs can best be met within national priorities, for example:

- New Anglia LEP has begun a green economy which aims to help foster the necessary conditions and success factors for private sector and inward investment to develop the strategic Low Carbon and Environmental Goods and Services (LCEGS) supply chain.

- Business Link are working with Stoke and Staffs, Tees Valley and Cheshire and Warrington and Manchester LEPs to demonstrate how the Business Link offer can be syndicated to LEPs.

- Tees Valley Unlimited partnership is working with the main business organisation, NEPIC, UKTI, BIS (YHNE) and BIS chemicals team to assess and promote opportunities for attracting new investment to the Wilton Chemical Cluster Site.

- Working alongside other LEPs with common interests to ensure a coordinated approach to growth activity, for example, LEPs with an interest in aerospace are engaged with national policy leads and each other through the Aerospace Local Engagement Group and in those with an interest in automotive through the Automotive interest Group.

Local authorities in each region were working on developing proposals for LEPs for submission to Government. There are, however, two sponsoring departments, and ministers, taking a different view. On the one hand, the Department for Communities and Local Government says there will be little or no ministerial intervention in the process of forming LEPs, with the partnerships not needing to be 'signed off' by government. On the other hand, the Department for Business, Innovation and Skills says the plans will be submitted to a process of review and ministerial approval, and that those which fail to meet the central requirement that they cover a 'natural economic area', will be weeded out. Early indications are that only about 10 to 15 of the proposals are 'any good' and that the Government is likely approve 10 as 'Trail Blazers' (Finch, 2010) ${ }^{8}$. In mid September BIS Secretary Vince Cable said that three quarters of the proposed LEPs would need 'a lot of work' and that they are 'hopelessly fragmented and will have to get their act together' (Bailey, 2010b). We turn to look at two contrasting case examples of discussions in the regions about LEPs; the West Midlands, where they were unable to agree to a proposal for a region wide LEP and, Yorkshire and Humberside, where there was agreement that the region should have a region-wide LEP. In the event, the YEP did not submit a proposal and, at the last minute,

\section{A. New economic policy towards localism : New Approach towards Collaboration between different public and private sector bodies across administrative boundaries :}

- The Government argued that the devolution of powers to regions,comprising 'natural' or 'functional' units, in the form of LEPs offers a more effective reference point for the co-ordination of public policies and resources (New Local Government Network, 2009). It is expecting that they will tackle a wide range of policy issues that contribute to creating the right environment for business and growth in their

\footnotetext{
${ }^{7}$ Same as above

${ }^{8}$ From RDAs to LEPs: A New Localism? Case Examples of West Midlands and Yorkshire - Gill Bentley David Bailey and John Shutt Local Economy September 2010 vol. 25 no. 7 535-557
} 
areas including planning and housing, local transport and infrastructure priorities, employment and enterprise and the transition to the low carbon economy?

- There may be a possibility that the new LEPs will face the same set of challenges. Indeed, removing the regional strategic planning tier risks squandering the benefits of coordination and could lead to more disputes arising at the local level, where competition could well replace cooperation leading to greater uncertainty for both the private sector and public bodies.

- Institutional arrangements at the local level are also already crowded and the potential contribution of established mechanisms should not be ignored. But still there is failure of local authorities in economic development through Local Partnerships in business development and public private partnership on development projects.

\section{Retaining strategic capacity and expertise:}

- The transfer of planning and economic functions to the local level can be regarded as a response to the limited accountability of the Leaders and the Regional Development Agencies. Nonetheless, tensions over the weight to be given to economic development, environmental protection and housing policies will remain, underlining, as there is a need for a coordinated rather than a set of singular local authority or sectoral responses.

- A key strength of the development plan system is that is that it provides a comprehensive approach to the development of an area in a publicly accountable environment, counter-balancing the tendency towards undue influence by single-issues. By contrast, LEPs are expected to have a business orientation and while business interests are important they should not automatically take precedence over other economic, social and environmental priorities.

- If LEPs were to take over a significant element of the development plan function this would not only give rise to alarm in communities, but also potentially discourage business sector involvement in policy areas in which they are neither willing nor able to engage. Indeed, the inclusion of planning and other key policy areas could threaten what will be new and potentially fragile relationships between business and local authorities in emerging LEPs.

- Since the abolition of spatial planning at the regional level and the transfer of this function to local authorities, and the establishment of Local Enterprise Partnerships (LEPs) ${ }^{10}$, are held to offer a more effective and accountable approach to regional level planning but it is still very much unclear what kind of role the new establishment will play in planning. Nevertheless, there are potential contradictions, uncertainties and costs arising from changes to the planning system, which carry significant risks for the delivery of key policies.

So, we can conclude by stating that the,

\section{Conclusion}

- The legacy of regional working should not be dissipated.

- The absence of a national spatial planning strategy and limited spatial awareness in key spending departments will continue to undermine efforts to coordinate disparate public funding streams and provide the continuity necessary to deliver private sector investment at the regional tier.

- There is no right scale of government at which spatial planning should be pursued. Nevertheless, there is an array of key long-term, cross-cutting issues that demands strategic responses from both public and private sectors and vary in their impact within and between regions, but which transcend the capacities of individual local authorities.

- Removing the statutory regional planning tier will undermine efforts to secure sustainable patterns of development, especially in accommodating urban growth in the Greater South East and tackling regional economic inequalities.

\footnotetext{
${ }^{9}$ Burgess, G., Monk, S. and Whitehead, C. (2010) How can the planning system deliver more housing? Joseph

Rowntree Foundation, York.

${ }^{10}$ Conservative Party. (2009) Control shift: Returning power to local authorities, Responsibility Agenda Policy Green Paper No.9, Conservative Party, London.
} 
- The proposed LEPs could provide a mechanism for dealing with a range of cross cutting issues relating to economic development, but they will not be wholly elected and may not be statutory bodies. As such they are likely to replicate the same weaknesses of legitimacy associated with the unelected regional assemblies and RDAs.

- The business sector is expected to voluntarily engage in LEPs, but business partners do not want to be part of bureaucratic 'talking shops'. Local authorities will, therefore, face the dilemma of having to balance private business interests with public interests, including a complex array of social and environmental issues.

\section{Selected Reference and bibliography:}

\section{References:}

[1]. Tony Jackson..,(February 2007)Mainstreaming sustainability in Local Economic Development Proactive, Local Economy, Vol.22, No.1, February 2007.

[2]. Birmingham core strategy 2026, A plan for sustainable growth, consultation draft, December 2010

[3]. I. Fernandez, M.C. Ruiz (2009) Descriptive model and evaluation system to locate sustainable industrial areas, Journal of Cleaner Production 17.

[4]. Marco Bontje.,(July2004)Sustainable new economic centers in European Metropolitan Regions: a Stakeholders' perspective, European planning studies, Vol.12, No.5, July 2004,

[5]. Philip R. Berke, Are we planning for sustainable development?, APA Journal, Vol.66, No.1, Winter 2000, Maria Manta Conroy

[6]. Stephen M. Wheeler, The Evolution of built landscapes in metropolitan regions, Journal of planning education and research, 27; 400; 2008,

[7]. Stephen M. Wheeler ,Planning for sustainability, Contemporary concerns of planning,

[8]. Solihull draft Local Plan, Shaping a sustainable future, Local development framework, pre-submission draft January 2012

[9]. Regional spatial strategy for the West Midlands, Government office for the West Midlands, January 2008

[10]. Green Deal, Department of Energy and Climate Change, 2010

[11]. What Price West Midlands Green Belts?, Campaign to Protect Rural England, June 2007

[12]. The Planning System: General Principles, Office of the deputy Prime Minister, 2005

[13]. Environmental report on the revocation of the Regional Spatial Strategy for the West Midlands, Communities and Local Government, October 2011

[14]. Local Authority Revenue Expenditure and Financing England 2011-12 budget, Department of Communities and Local Government, $30^{\text {th }}$ June 2011.

[15]. Prof. Peter Tyler, Expert Evaluation Network Delivering Policy Analysis on the performance of cohesion policy 2007-2013, A report to the European Commission Directorate-General Regional Policy November2010,

[16]. Economic and Social Research Strategy 2011-12, An overview of Economic and Social Research, February 2012, Department of Business, Innovation and Skills.

[17]. National Planning Policy Framework: March 2012, Department for Communities and Local Government, England.

[18]. Abolition of Regional Spatial Strategies: A planning vacuum, Second Report of Session 2010-11, Volume 1, February 2011, House of Commons Communities and Local Government Committee.

[19]. Modernizing Local Government Finance: A Green Paper, Department for Transport, Local Government and the Regions, September 2000. 